are not only trying to find common ground for studying natural and man-made forms by comparative methods, but are also succeeding. Here, indeed, is a book to help them. F. I. G. RAwLINS

\section{ZOOLOGICAL LITERATURE OF 1950}

\section{The Zoological Record}

Vol. 87, being the Records of Zoological Literature relating chiefly to the Year 1950. Edited by G. Burder Stratton. Pp. vi+1507. (London: Zoological Society of London, 1953.)

THE serious student of zoology is greatly indebted to the Zoological Society of London for the production of the annual volumes of the "Zoological Record" in spite of continually increasing costs. It is difficult to imagine how any systematist could ever succeed in tracing the literature of his subject without this annual list of titles of zoological papers, published usually within thirty months or less of the end of the year to which any particular volume relates. The present volume, No. 87, deals principally with the literature of 1950 and comprises more than thirteen thousand references, classified into eighteen sections, and a final chapter giving a list of new generic and sub-generic names.

The activity in different branches of the subject is to some extent indicated by the number of titles in each section, ranging from Porifera, with only sixty-six titles, up to Insecta, which overwhelms all other sections with a total of 3,101 titles, almost a quarter of the whole volume. A glance through these sections reveals some rather unexpected figures, for under Aves one finds more than sixty new species and subspecies recorded, although the ordinary zoologist would have imagined that at least in this class very few new forms remain to be discovered.

Each section begins with a list of titles followed by a subject index briefly indicating the papers dealing with particular branches. Thus the subject index of Protozoa has sections on text-books, history, biography and obituary, bibliography, taxonomy, technique, structure, physiology, locomotion, sexuality, effects of environment and stimuli, effects of chemicals, development, evolution and genetics, ecology (including parasitism), economics and distribution (both geographical and geological) and, finally, a systematic index. The sections may be purchased separately from the Zoological Society of London (Regent's Park, London, N.W.8), except for the section "Insecta", which is obtainable only from the Commonwealth Institute of Entomology (41 Queen's Gate, London, S.W.7). It is rather surprising that, judging from the sales, more use is not being made of these sections of the "Zoological Record", for as a result of various donations they are supplied at a price far below the cost of production.

Zoologists are greatly indebted to the specialists responsible for the compilation of the various sections, and whose services are obtained more or less on a voluntary basis. One notable change occurs on the title page. The present volume is edited by Mr. G. Burder Stratton, librarian of the Zoological Society of London, whose name replaces Dr. A. Malcolm Smith, who has been editor of the "Record" since 1938 and to whom zoologists throughout the world owe a special debt of gratitude for his valuable services.

\section{INDIA'S FOOD PROBLEMS}

\section{Food and Population and Development of Food} Industries in India

Pp. xv +357 . (Mysore: Central Food Technological Research Institute, 1952.) $10 s$.

$\mathrm{O}^{\mathrm{r}}$ all the free nations of the world, few have more difficult food problems than the Union of India. The population is about 357 millions, an increase of some 40 millions over that of 1941 ; the area of sown land per head in 1951 was 0.6 acre and has long been shrinking, for in 1911 it was 0.9 acre. This shrinking area has to provide not only food but also cash crops, especially cotton and non-edible oil seeds. Some land is still unused, but it usually has some disability more or less difficult or costly to remove; there is still the possibility of more irrigation which would enable the land to carry two crops a year instead of one and also to givo higher and more certain yields. But meanwhile the health services are improving: anti-malarial operations are saving great numbers of lives, and it has been estimated that, even if all the optimistic plans of 1951 could be carried through, the nation's food position in 1956 would be no better than it. is to-day.

One of the most hopeful features in this difficult situation is the seriousness with which Indian agriculturists and food experts are dealing with it. The numerous problems involved were discussed in two impressive symposia held in May 1951 at the Central Food Technological Research Institute in Mysore, a remarkable organization under the direction of Dr. V. Subrahmanyan: both food production and food processing were dealt with. The papers are collected in this volume, and they give an admirable summary of the ideas and methods of the Indian experts and of the problems as they then stood.

The discussions ranged chiefly around the possibilities of increasing production of food grains, of increasing yields of all crops, improving methods of storage and preservation, reducing wastes and losses, and utilizing more widely foods at present confined to certain localities but capable of considerably higher output per acre than those at present grown. The main facts are already well documented; but they are set out here with great clarity and in handy form. If there is a certain amount of repetition, it is justified by the grim importance of the subject.

Serious complications arise in India from the circumstance that the choice of food is governed not simply by economic but also by social and religious factors : custom especially plays a large part. Great numbers of the population will eat only rice as their staple food, although cassava would give much higher yields per acre. Dr. Subrahmanyan has ingeniously made a 'synthetic rice' by moulding a mixture of tapioca and groundnuts into grains of the size and shape of rice grains; how far these will prove acceptable remains to be seen. Other possibilities discussed include the utilization as human food of various oilseed residues, groundnut and others, at present fed to cattle or used as manure. The current grain shortage is about 10 per cent of the total consumption, but this is increasing yearly : Indian agricultural experts are making great efforts to narrow or even close the gap. 'The book gives an excellent description by the workers themselves of the way they are setting about their task.
E. JoHn Russell 